Cahiers d'études africaines

\title{
Bornand, Sandra. - Le discours du griot généalogiste chez les Zarma du Niger
}

Paris, Karthala, 2005, 458 p.

Jean-Pierre Olivier de Sardan

\section{OpenEdition}

\section{Journals}

Édition électronique

URL : http://journals.openedition.org/etudesafricaines/6268

DOI : 10.4000 /etudesafricaines.6268

ISSN : $1777-5353$

\section{Éditeur}

Éditions de l'EHESS

Édition imprimée

Date de publication : 1 décembre 2006

ISBN : 978-2-7132-2129-3

ISSN : 0008-0055

\section{Référence électronique}

Jean-Pierre Olivier de Sardan, « Bornand, Sandra. - Le discours du griot généalogiste chez les Zarma du Niger », Cahiers d'études africaines [En ligne], 184 | 2006, mis en ligne le 08 décembre 2006, consulté le 21 septembre 2020. URL : http://journals.openedition.org/etudesafricaines/6268 ; DOI : https:// doi.org/10.4000/etudesafricaines.6268

Ce document a été généré automatiquement le 21 septembre 2020.

(c) Cahiers d'Études africaines 


\section{Bornand, Sandra. - Le discours du griot généalogiste chez les Zarma du Niger}

Paris, Karthala, 2005, 458 p.

Jean-Pierre Olivier de Sardan

1 Sandra Bornand a recueilli, au fil de nombreux séjours dans l'ouest du Niger, pays de langue zarma, un très remarquable corpus de "traditions orales", au sens le plus large : déclamations de griots, généalogies, récits épiques, contes, proverbes chantés, louanges, etc. La plus grande partie de ce corpus a pour auteur un jasare (maître-griot) zarma, Djéliba Badjé, de grande réputation locale, avec lequel elle a noué une longue et fertile collaboration.

2 Un certain nombre de «textes oraux " issus de ce corpus figurent dans un cédérom joint à l'ouvrage. Autrement dit, le cédérom propose des récits et louanges transcrits en zarma, leurs traductions françaises, un appareil de notes critiques, ainsi qu'une partie des enregistrements originaux à écouter (et, pour qui comprend le zarma, à savourer). On a affaire là au cœur même du travail au long cours de Sandra Bornand, et on doit souhaiter que le reste du corpus soit bientôt mis lui aussi à la disposition des spécialistes.

3 Il s'agit en effet d'une entreprise exceptionnelle, relevant de ce qu'on a parfois appelé l'« ethnographie de sauvetage »: Djéliba Badjé est en effet sans doute le dernier des grands maîtres-griots zarma. Aucun de ses nombreux enfants ne va en effet lui succéder (comme cela aurait été le cas une ou deux générations auparavant), les « écoles de griots au coin du feu » ont disparu dans tout le pays, et les quelques maîtresgriots qui déclament encore semblent être les derniers du genre. Les temps changent : multiplication des griots-quémandeurs dépourvus de ce savoir généalogique, musical, linguistique et historique accumulé patiemment par les maîtres-griots d'antan, évolution des mœurs et quête de l'argent facile, concurrence de l'école, pression d'un islam de plus en plus intolérant... 
4 La forme choisie (cédérom) est sans doute appropriée à la sauvegarde érudite d'un tel corpus, en permettant un accès à la fois multidimensionnel (texte, image, son) et peu coûteux. Mais je regrette pour ma part que la conséquence en soit la disparition (sur exigence de l'éditeur) de tout texte oral zarma du livre lui-même. Ceci est paradoxal dans la mesure où cet ouvrage est consacré pour une grande part à l'analyse de textes... qui en sont d'une certaine façon absents (il faut en effet obligatoirement se reporter au cédérom pour en prendre connaissance).

Ce livre n'en est pas moins particulièrement riche. Sa structure foisonnante nous emmène dans de nombreuses directions, relevant de genres et de focales assez différents. On y trouve ainsi des « états de la question » de bonne facture, synthétiques certes mais qui seront fort utiles au non-spécialiste, tant sur la « littérature orale » et l'ethnolinguistique africaniste, que sur le Niger ou les Songhay-Zarma. Quant au bilan des travaux sur la langue et la culture zarma depuis un siècle, il n'est pas loin d'être exhaustif (on trouvera par exemple la liste de tous les textes oraux songhay-zarma enregistrés et transcrits, au moins au Niger) et il comble incontestablement un vide. On débouche ensuite sur des analyses plus personnelles de l'auteure à propos du rôle et du pouvoir de la parole dans la société traditionnelle zarma, de la notion complexe de «lakkal» (entre intelligence, savoir-vivre, et maittrise des codes sociaux) déjà étudiée par Diouldé Laya, ou des genres discursifs locaux (les quelques pages sur la mémoire sont, en revanche, décevantes). Le parcours se poursuit (chapitres 7 et 8 , mais aussi chapitre 14) avec des descriptions particulièrement convaincantes consacrées aux divers types de griots songhay-zarma, à la spécificité des maitres-griots, à l'ambiguïté de leur statut social (entre esclaves et hommes libres), aux rapports particuliers qu'ils entretiennent avec l'aristocratie locale, au mode de transmission de leurs savoirs, à leurs stratégies professionnelles et performatives. C'est là, incontestablement, la partie la plus achevée et la plus originale de l'ouvrage, où Sandra Bornand fait œuvre d'anthropologue confirmée, apportant des connaissances nouvelles et précieuses. Enfin, la troisième partie est toute entière consacrée à de longues analyses ethnolinguistiques, de facture classique, portant sur les textes oraux du cédérom. De tels commentaires érudits ne sont certes pas faciles à suivre pour le non-spécialiste, mais ils relèvent d'un genre qui a ses titres de noblesse et qui est ici maîtrisé.

Cet ouvrage est parfois à lire d'un trait, parfois à consulter (à cet égard, on déplorera l'absence d'un index). Il doit en tout cas figurer dans la bibliothèque de quiconque s'intéresse aux cultures nigériennes. Et l'auteure a suscité désormais une attente : nous espérons en effet qu'elle nous permettra bientôt d'avoir accès à l'ensemble de ce trésor qu'elle a accumulé, et dont elle ne nous a donné ici que quelques pépites. Les textes oraux zarma constituent en effet un patrimoine précieux et menacé dont Sandra Bornand est devenue, à divers égards, dépositaire. 